\title{
Effective Sequential Combined Chemotherapy with Trifluridine/Tipiracil and Regorafenib in Human Colorectal Cancer Cells
}

\author{
Kazuaki Matsuoka ${ }^{1, *}$, Fumio Nakagawa ${ }^{2}$, Nozomu Tanaka ${ }^{3}$, Hiroyuki Okabe ${ }^{4}$, \\ Kenichi Matsuo ${ }^{5}$ and Teiji Takechi ${ }^{1}$ \\ 1 Translational Research Laboratory, Taiho Pharmaceutical Co., Ltd., 224-2, Ebisuno Hiraishi, Kawauchi-Cho \\ Tokushima, Tokushima 771-0194, Japan; ttakechi@taiho.co.jp \\ 2 Applied Pharmacology Laboratory, Taiho Pharmaceutical Co., Ltd., 224-2, Ebisuno Hiraishi, Kawauchi-Cho \\ Tokushima, Tokushima 771-0194, Japan; f-nakagawa@taiho.co.jp \\ 3 Drug Discovery \& Development I Laboratory, Taiho Pharmaceutical Co., Ltd., 3, Okubo, Tsukuba, \\ Ibaraki 300-2611, Japan; noz-tanaka@taiho.co.jp \\ 4 Product Promotion, Taiho Pharmaceutical Co., Ltd., 1-2-4 Uchikanda, Chiyoda-ku, Tokyo 101-0047, Japan; \\ h-okabe@taiho.co.jp \\ 5 Pharmacology Laboratory, Taiho Pharmaceutical Co., Ltd., 3, Okubo, Tsukuba, Ibaraki 300-2611, Japan; \\ matsuken@taiho.co.jp \\ * Correspondence: kazu-matsuoka@taiho.co.jp; Tel.: +81-88-665-5337
}

Received: 17 August 2018; Accepted: 21 September 2018; Published: 25 September 2018

\begin{abstract}
Salvage chemotherapy for refractory metastatic colorectal cancer using trifluridine/tipiracil (FTD/TPI) and regorafenib has shown survival benefits. We evaluated the antitumor effects of FTD or FTD/TPI combined with regorafenib in vitro and in vivo. SW620, HCT 116, and HT-29 human colorectal cancer cell lines were treated with FTD and regorafenib simultaneously and sequentially. Cell death, incorporation of FTD into DNA, and molecules related to FTD and regorafenib-associated cell death were investigated. The antitumor effects of FTD combined with regorafenib in SW620 and COLO205 xenografts were also evaluated. Cell death was greater after sequential treatment with FTD followed by regorafenib in SW620 cells, but not in HCT 116 and HT-29 cells, than after treatment with FTD alone, which was attributable to thymidylate synthase reduction with the induction of apoptosis. In contrast, simultaneous and sequential exposure to regorafenib followed by FTD, but not FTD alone, attenuated the cell death effect. Furthermore, combined FTD/TPI treatment followed by regorafenib had greater antitumor activity than either monotherapy in SW620 and COLO205 xenograft models. Treatment results following regorafenib administration subsequent to FTD or FTD/TPI suggest that sequential therapy with FTD/TPI prior to regorafenib may be effective in a clinical setting.
\end{abstract}

Keywords: trifluridine; tipiracil hydrochloride; TAS-102; regorafenib; colorectal cancer

\section{Introduction}

Colorectal cancer (CRC) is the third most commonly diagnosed cancer worldwide [1]. The management of patients with metastatic CRC (mCRC) requires systemic administration of cytotoxic drugs. Patients with mCRC who receive chemotherapy have a median overall survival (OS) of more than 2 years [1], whereas those receiving standard care alone have a median OS of 5 months [1,2]. Combination therapies using 5-fluorouracil (5-FU)/leucovorin (LV) and oxaliplatin (FOLFOX), as well as 5-FU/LV and irinotecan hydrochloride (FOLFIRI), have been established as effective cytotoxic regimens for the treatment of $\mathrm{mCRC}$ [1]. 
Trifluridine/tipiracil (FTD/TPI, also known as TAS-102) is a combination treatment including FTD and TPI at a molar ratio of 1:0.5. FTD, an antineoplastic thymidine analog [3], is the active antitumor component of FTD/TPI [4,5]. FTD inhibits thymidylate synthase when in its monophosphate form [6] and incorporates into DNA when in its triphosphate form, thereby inhibiting DNA synthesis and resulting in antitumor activity. TPI potently inhibits thymidine phosphorylase [7], an enzyme that degrades FTD. Therefore, TPI helps maintain adequate concentrations of orally administered FTD in the plasma [7], potentiating its antitumor activity. Improvements in OS in patients receiving FTD/TPI treatment were better than those in patients receiving placebo in a global randomized phase III trial (RECOURSE), which included patients with mCRC refractory to standard chemotherapy [8]. FTD/TPI is approved in Japan, the United States, and the European Union, and other countries, for the treatment of unresectable advanced or recurrent colorectal cancer.

Regorafenib is an oral multikinase inhibitor that blocks the activity of several protein kinases associated with angiogenesis, oncogenesis, and the tumor microenvironment [9]. OS was shown to be longer in patients with mCRC refractory to standard chemotherapy receiving regorafenib than in patients receiving a placebo in a randomized phase III trial (CORRECT) [10]. As with FTD/TPI, regorafenib is recognized as a standard treatment for patients with refractory mCRC. Clinical retrospective evaluations have been reported using data from patients who received FTD/TPI or regorafenib in terms of efficacy and safety, suggesting that FTD/TPI and regorafenib have a similar effect on OS but different toxicities [11,12]. However, the administration sequence of these drugs and mechanisms of action in preclinical studies have not been investigated in detail.

In this study, we investigated whether cytotoxicity was enhanced when FTD was used simultaneously or sequentially with regorafenib in vitro. Furthermore, we evaluated the antitumor effects of FTD in combination with regorafenib using in vivo human tumor xenograft models.

\section{Results}

\subsection{Cell Death after Sequential Administration of FTD Followed by Regorafenib}

We evaluated the efficacy of simultaneous treatment with FTD and regorafenib for $24 \mathrm{~h}$ in SW620, HCT 116, and HT-29 cells, as well as the sequential combination of the two drugs (FTD for $24 \mathrm{~h}$ followed by regorafenib for $24 \mathrm{~h}$ or vice versa) using a clonogenic cell survival assay. A fixed concentration of $10.0 \mu \mathrm{M}$ regorafenib, based on the $\mathrm{IC}_{50}$ value for regorafenib alone determined in SW620 cells, was used for this experiment (data not shown). Figure 1A shows the treatment schedule for the two drugs. Figure 1B-D show the results obtained after simultaneous exposure to FTD and regorafenib, the sequential combination of FTD followed by regorafenib, and the sequential combination of regorafenib followed by FTD in SW620, HCT 116, and HT-29 cells, respectively. After simultaneous exposure, the surviving fraction (SF) gradually decreased with increasing concentrations of FTD up to $4.0 \mu \mathrm{M}$ (Figure 1B-D); the SF values were significantly greater than those in cells treated with FTD alone for all three cell lines $(p<0.01)$. Similar to results from the simultaneous exposure experiment, SF values after sequential exposure to regorafenib followed by FTD were significantly greater than those after exposure to FTD alone in all three cell lines $(p<0.05$ and 0.01). Further, cell death was observed to a lesser extent after simultaneous treatment with FTD and regorafenib and sequential treatment with regorafenib followed by FTD than after treatment with FTD alone.

SF values after the sequential combination (FTD followed by regorafenib) treatment were comparable to those after treatment with FTD alone in both HCT 116 and HT-29 cells. In contrast, SF values after sequential exposure to FTD $(1.0$ and $2.0 \mu \mathrm{M})$ followed by regorafenib in SW620 cells were significantly lower $(p<0.01$ for $2.0 \mu \mathrm{M}$ FTD and $p<0.05$ for $4.0 \mu \mathrm{M}$ FTD) than those after exposure to FTD alone. 
A)

$\operatorname{FTD}(0.1,0.5,1,2,4 \mu \mathrm{M})$

$\square$ Regorafenib $(10 \mu \mathrm{M})$

\ FTD + Regorafenib

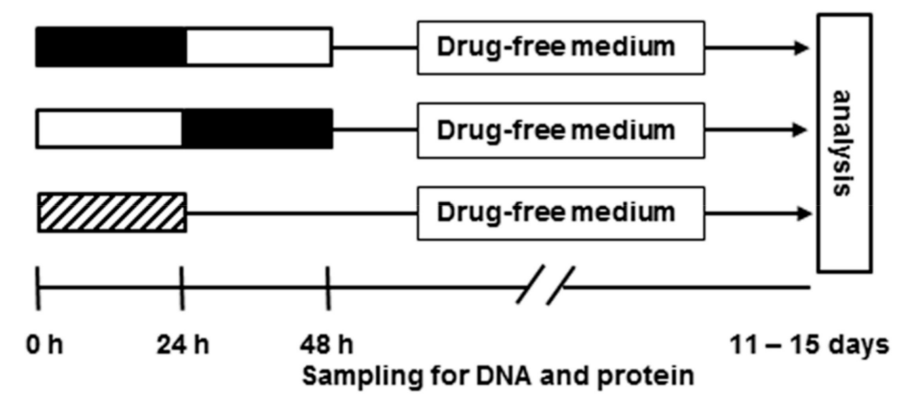

B)
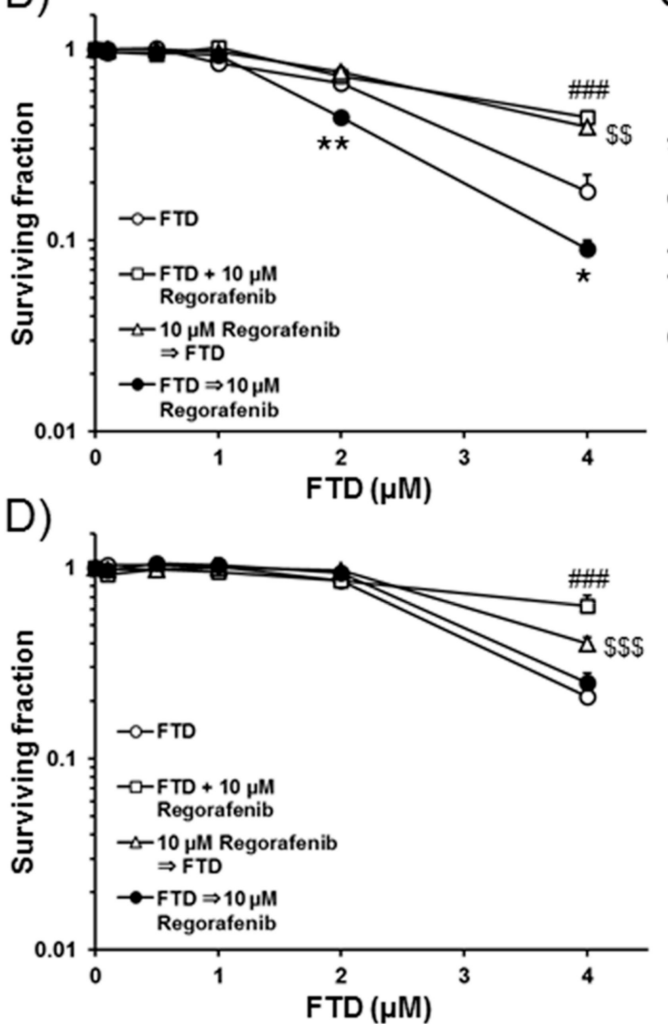

C)

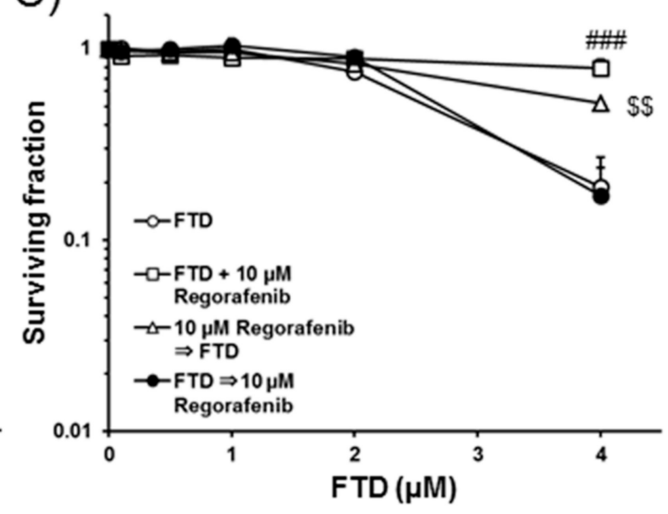

Figure 1. A clonogenic cell survival assay of trifluridine (FTD) and regorafenib using various treatment schedules in SW620, HCT 116, and HT-29 cells. (A) Treatment schedules are shown. Cells were plated at appropriate concentrations in duplicate in six-well plates. SW620 (B), HCT 116 (C), and HT-29 (D) cells were exposed to 0.1-4.0 $\mu \mathrm{M}$ FTD alone, in combination with 0.1-4.0 $\mu \mathrm{M}$ FTD and $10.0 \mu \mathrm{M}$ regorafenib for $24 \mathrm{~h}, 0.1-4.0 \mu \mathrm{M}$ FTD for $24 \mathrm{~h}$ followed by $10.0 \mu \mathrm{M}$ regorafenib for $24 \mathrm{~h}$, or $10.0 \mu \mathrm{M}$ regorafenib for $24 \mathrm{~h}$ followed by $0.1-4.0 \mu \mathrm{M}$ FTD for $24 \mathrm{~h}$. Eleven to fifteen days after removal of the drug, the number of colonies was determined. Data from three independent experiments are presented as the mean + standard deviation (SD); surviving fraction (SF) in 0.1-4.0 $\mu \mathrm{M}$ FTD followed by $10.0 \mu \mathrm{M}$ regorafenib or regorafenib followed by FTD was calculated by assuming a SF of 1.0 when cells were treated with $10.0 \mu \mathrm{M}$ regorafenib alone for $24 \mathrm{~h}$. Mean SF values for the sequential combination of 2.0 or $4.0 \mu \mathrm{M}$ FTD followed by $10.0 \mu \mathrm{M}$ regorafenib in SW620 cells are shown. ${ }^{*} p<0.05$ and ${ }^{* *} p<0.01$ represent significant differences compared with 2.0 or $4.0 \mu \mathrm{M}$ FTD alone. \#\#\# $p<0.001, \$ \$ p<0.01$, and $\$ \$ \$<0.001$ represent significant differences compared with $4.0 \mu \mathrm{M}$ FTD alone. 


\subsection{Incorporation of Trifluridine (FTD) into Genomic DNA}

FTD incorporates into DNA when in its triphosphate form. Therefore, we examined whether incorporation of FTD into DNA differed after simultaneous or sequential exposures to FTD and regorafenib in SW620, HCT 116, and HT-29 cells, as shown in Figure 2. When the cells were simultaneously treated with $4.0 \mu \mathrm{M}$ FTD and $10.0 \mu \mathrm{M}$ regorafenib for $24 \mathrm{~h}$, incorporation of FTD into DNA was $60 \%$ that of controls ( $4.0 \mu \mathrm{M}$ FTD alone for $24 \mathrm{~h}$ ) in SW620 and HCT 116 cells (for both, $p<0.001)$, and about $80 \%$ that of controls in HT-29 cells $(p<0.01)$. Although incorporation of FTD into DNA was significantly less than that observed in control $2(4.0 \mu \mathrm{M}$ FTD for $24 \mathrm{~h}$ followed by drug-free for $24 \mathrm{~h}$ ), incorporation of the remaining FTD into DNA was approximately 77\% in SW620 cells even after sequential exposure to $4.0 \mu \mathrm{M}$ FTD for $24 \mathrm{~h}$ followed by $10.0 \mu \mathrm{M}$ regorafenib for $24 \mathrm{~h}$; for comparison, incorporation of the remaining FTD into DNA was approximately $112 \%$ and $106 \%$ that of control 2 in HCT 116 and HT-29 cells, respectively. In contrast, incorporation of FTD into DNA after sequential exposure to $10.0 \mu \mathrm{M}$ regorafenib for $24 \mathrm{~h}$ followed by $4.0 \mu \mathrm{M}$ FTD for $24 \mathrm{~h}$ was $83 \%$, $57 \%$, and 75\% lesser in SW620 ( $p<0.05)$, HCT $116(p<0.001)$, and HT-29 cells $(p<0.01)$, respectively, than that in control 3 (drug-free for $24 \mathrm{~h}$ followed by $4.0 \mu \mathrm{M}$ FTD for $24 \mathrm{~h}$ ). These results suggest that regorafenib inhibits the incorporation of FTD into DNA when cells are simultaneously exposed to FTD and regorafenib, as well as during sequential exposure to regorafenib followed by FTD.

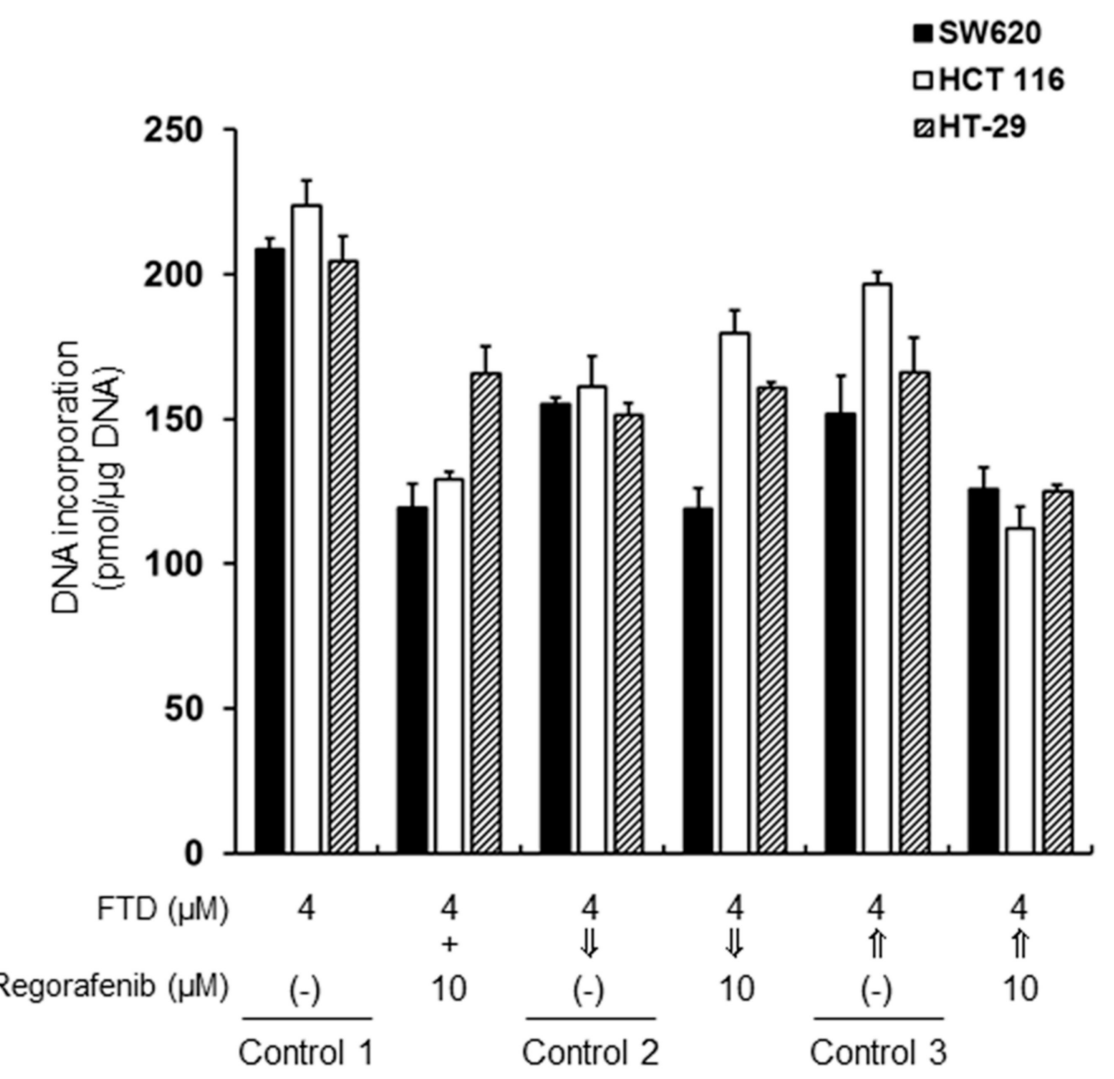

Figure 2. Incorporation of trifluridine (FTD) into DNA. SW620, HCT 116, and HT-29 cells were treated with $4.0 \mu \mathrm{M}$ FTD and $10.0 \mu \mathrm{M}$ regorafenib for $24 \mathrm{~h}, 4.0 \mu \mathrm{M}$ FTD for $24 \mathrm{~h}$ followed by $10.0 \mu \mathrm{M}$ regorafenib for $24 \mathrm{~h}$, or regorafenib followed by FTD. Double-stranded DNA was extracted, and FTD incorporation was determined via liquid chromatography/tandem mass spectrometry (LC/MS/MS).

Data are presented as the mean $+\mathrm{SD}(n=3)$.

\subsection{Drugs and Apoptosis-Related Protein Expression Following the Combination Treatment}

We investigated whether drug treatment schedules might influence apoptosis and the expression of phosphorylated extracellular signal-related kinase 1/2 (p-ERK1/2), ERK1/2, and thymidylate 
synthase (TS); the former and latter are major determinants of the sensitivity of cells to regorafenib and FTD, respectively. The results of the western blot analyses are shown in Figure 3. Similar to a previous report by Schmieder et al. [13], regorafenib alone $(10.0 \mu \mathrm{M})$ reduced p-ERK1/2 levels in HCT 116 and HT-29 cells, whereas p-ERK1/2 returned to baseline levels in SW620 cells. Consistent with previous results [14,15], FTD alone $(1.0$ and $4.0 \mu \mathrm{M})$ increased p-ERK1/2 levels in HCT 116 cells. In contrast, p-ERK1/2 was not altered in HT-29 cells and was decreased in SW620 cells. Additionally, p-ERK1/2 levels were lower after simultaneous exposure to FTD $(1.0 \mu \mathrm{M}$ or $4.0 \mu \mathrm{M})$ and regorafenib $(10.0 \mu \mathrm{M})$ for $24 \mathrm{~h}$ or sequential exposure to FTD $(1.0 \mu \mathrm{M}$ or $4.0 \mu \mathrm{M})$ for $24 \mathrm{~h}$ followed by regorafenib $(10.0 \mu \mathrm{M})$ for $24 \mathrm{~h}$ than the levels in untreated control cells. A reduction in p-ERK1/2 levels in HCT 116 and HT-29 cells was clearly observed. Conversely, p-ERK1/2 levels in HCT 116 and HT-29 cells recovered after sequential exposure to regorafenib $(10.0 \mu \mathrm{M})$ for $24 \mathrm{~h}$ followed by FTD $(1.0 \mu \mathrm{M}$ or $4.0 \mu \mathrm{M})$ exposure for $24 \mathrm{~h}$. No effect on total ERK1/2 expression was observed for all treatment schedules in all three cell lines.

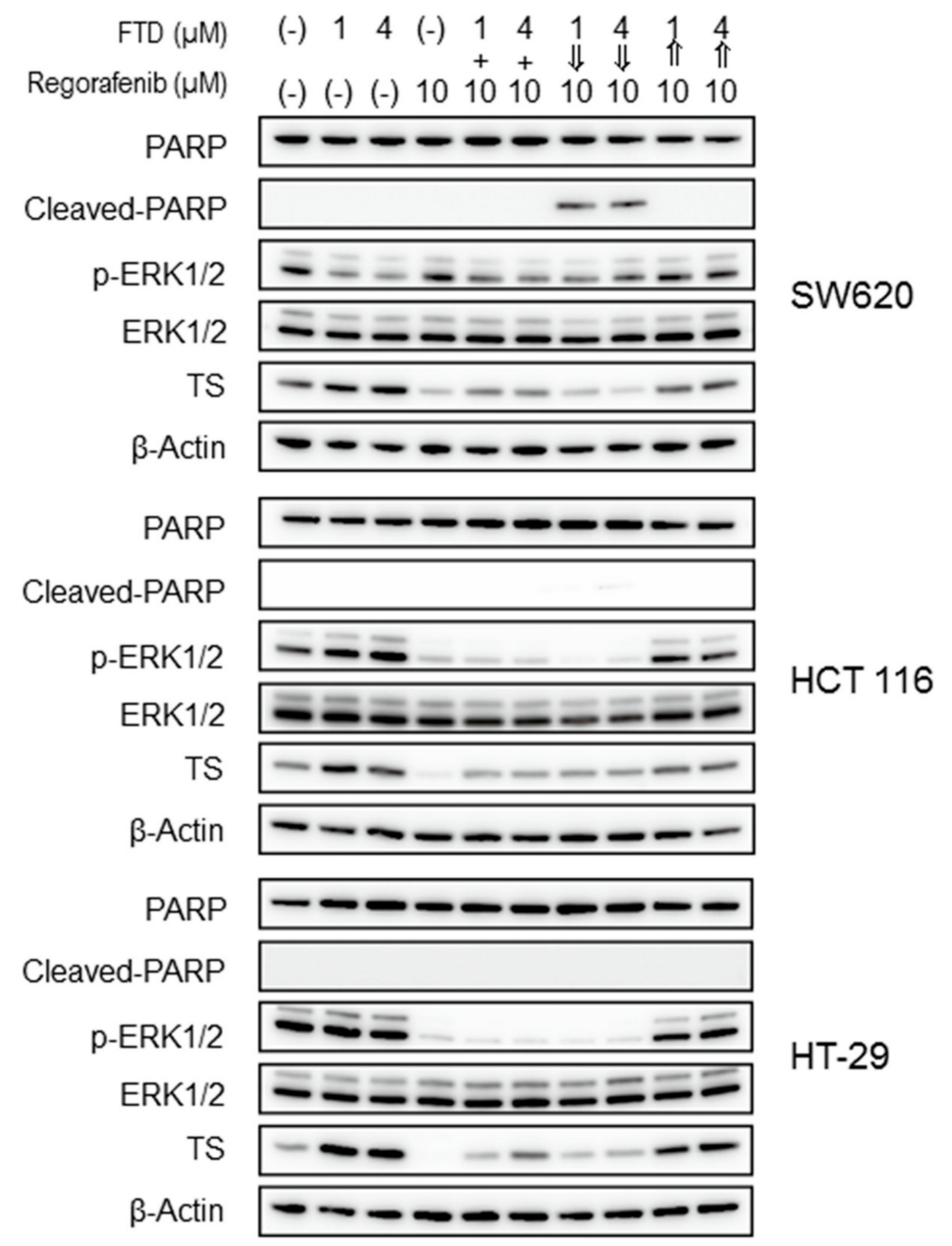

Figure 3. Effects on the expression of phosphorylated extracellular signal-related kinase (p-ERK), ERK, thymidylate synthase (TS), and markers of cell death in SW620, HCT 116, and HT-29 cells using various trifluridine (FTD) and regorafenib treatment schedules. Immunoblots after treatment with 1.0 and $4.0 \mu \mathrm{M}$ FTD for $24 \mathrm{~h}, 10.0 \mu \mathrm{M}$ regorafenib for $24 \mathrm{~h}$, and simultaneous and sequential treatment with 1.0 and $4.0 \mu \mathrm{M}$ FTD and $10.0 \mu \mathrm{M}$ regorafenib using the same schedules mentioned above are shown. Definition: PARP - poly(ADP-ribose) polymerase. 
Treatment with TS inhibitors, such as 5-FU and raltitrexed, rapidly induce TS levels [16], and induction of TS following treatment with FTD alone (1.0 and $4.0 \mu \mathrm{M})$ was observed (Figure 3). In contrast, regorafenib reduced TS levels. Especially, the reduction of TS levels in SW620 cells was maintained even after sequential exposure to FTD $(1.0 \mu \mathrm{M}$ or $4.0 \mu \mathrm{M})$ for $24 \mathrm{~h}$ followed by regorafenib $(10.0 \mu \mathrm{M})$ for $24 \mathrm{~h}$. In contrast, TS levels were higher after simultaneous exposure to FTD $(1.0 \mu \mathrm{M}$ or $4.0 \mu \mathrm{M})$ and regorafenib $(10.0 \mu \mathrm{M})$ for $24 \mathrm{~h}$ and sequential exposure to regorafenib $(10.0 \mu \mathrm{M})$ for $24 \mathrm{~h}$ followed by FTD $(1.0 \mu \mathrm{M}$ or $4.0 \mu \mathrm{M})$ for $24 \mathrm{~h}$ than those after treatment with regorafenib alone. In both HCT 116 and HT-29 cells, the consistent reductions in TS shown in SW620 cells were not observed for all treatment schedules. Interestingly, cleavage of poly(ADP-ribose) polymerase (PARP), a proapoptotic marker of cellular apoptosis, was dramatically increased in SW620 cells after sequential exposure to FTD $(1.0 \mu \mathrm{M}$ or $4.0 \mu \mathrm{M})$ for $24 \mathrm{~h}$ followed by regorafenib $(10.0 \mu \mathrm{M})$ for $24 \mathrm{~h}$.

Collectively, FTD followed by regorafenib treatment reduced TS more than treatment with FTD alone; PARP cleavage, a proapoptotic marker, was also observed in SW620 cells.

\subsection{Administration of Regorafenib Subsequent to FTD/TPI Increases the Antitumor Effect}

To further evaluate the antitumor effects of a FTD/TPI and regorafenib combination in vivo, we selected SW620 colorectal cells showing significant cell death following treatment using a clonogenic cell survival assay, as shown in Figure 1B. We further selected COLO205 colorectal cells, as the antitumor effects of regorafenib were previously reported in these cells [9]. FTD/TPI $(150 \mathrm{mg} / \mathrm{kg})$ and regorafenib $(10 \mathrm{mg} / \mathrm{kg})$ either alone or in sequential combination were administered to mice bearing both SW620 and COLO205 colorectal tumors for 14 consecutive days. Tumor volumes and body weight changes (BWC) in SW620 and COLO205 xenografted mice are shown in Figure 4A,B and Figure $4 C, D$, respectively. Tumor growth was inhibited more in mice treated with FTD/TPI and regorafenib alone than in the controls $(p<0.01)$. Furthermore, the antitumor activity of combined FTD/TPI followed by regorafenib treatment was superior to that of either monotherapy in both SW620 and COLO205 xenografts, as shown in Tables 1 and $2(p<0.01)$. No severe adverse events were observed in the present study, including a greater than $20 \%$ reduction in body weight and toxic death. Thus, the combined FTD/TPI followed by regorafenib treatment was well tolerated.

Table 1. Anti-tumor effects of trifluridine/tipiracil (FTD/TPI) and regorafenib in mice implanted with SW620 human colorectal tumors.

\begin{tabular}{cccccc}
\hline Group & $\begin{array}{c}\text { Dose } \\
\text { (mg/kg/day) }\end{array}$ & Treatment & $n$ & $\begin{array}{c}\text { RTV } \\
\text { (mean } \pm \text { SD) }\end{array}$ & $\begin{array}{c}\text { TGI } \\
\text { (\%) }\end{array}$ \\
\hline Control & - & - & 6 & $29.94 \pm 3.40$ & - \\
FTD/TPI & 150 & $\begin{array}{c}\text { Day } 1-14 \\
\text { (b.i.d.) }\end{array}$ & 6 & $14.57 \pm 1.44^{\mathrm{a}}$ & 51.3 \\
$\begin{array}{c}\text { Day 1-14 } \\
\text { (q.d.) }\end{array}$ & 6 & $6.55 \pm 1.34^{\mathrm{a}}$ & 78.1 \\
$\begin{array}{c}\text { FTD/TPI followed } \\
\text { by Regorafenib }\end{array}$ & $150+10$ & - & 6 & $4.07 \pm 0.56^{\mathrm{a}, \mathrm{b}}$ & 86.4 \\
\hline
\end{tabular}

RTV: Relative tumor volume on day 15; TGI: Tumor growth-inhibition ratio on day 15; b.i.d.: bis in die; q.d.: quaque die; $^{\text {a }} p<0.01$ with a two-sided Aspin-Welch $t$-test, compared to control; ${ }^{b} p<0.01$ with a two-sided Aspin-Welch $t$-test, compared to either monotherapy. 
Table 2. Anti-tumor effects of trifluridine/tipiracil (FTD/TPI) and regorafenib in mice implanted with COLO205 human colorectal tumors.

\begin{tabular}{cccccc}
\hline Group & $\begin{array}{c}\text { Dose } \\
\text { (mg/kg/day) }\end{array}$ & Treatment & $n$ & $\begin{array}{c}\text { RTV } \\
\text { (mean } \pm \text { SD) }\end{array}$ & $\begin{array}{c}\text { TGI } \\
\text { (\%) }\end{array}$ \\
\hline Control & - & - & 6 & $22.83 \pm 2.07$ & - \\
FTD/TPI & 150 & $\begin{array}{c}\text { Day 1-14 } \\
\text { (b.i.d.) } \\
\text { Day 1-14 } \\
\text { (q.d.) }\end{array}$ & 6 & $7.02 \pm 1.02^{\mathrm{a}}$ & 69.3 \\
$\begin{array}{c}\text { Regorafenib } \\
\begin{array}{c}\text { FTD/TPI followed } \\
\text { by Regorafenib }\end{array}\end{array}$ & 10 & - & 6 & $1.76 \pm 0.29^{\mathrm{a}, \mathrm{b}}$ & 92.3 \\
\hline
\end{tabular}

RTV: Relative tumor volume on day 29; TGI: Tumor growth-inhibition ratio on day 29; b.i.d.: bis in die; q.d.: quaque die; ${ }^{a} p<0.01$ with a two-sided Aspin-Welch $t$-test, compared to control; ${ }^{b} p<0.01$ with a two-sided Aspin-Welch $t$-test, compared to either monotherapy.

A)

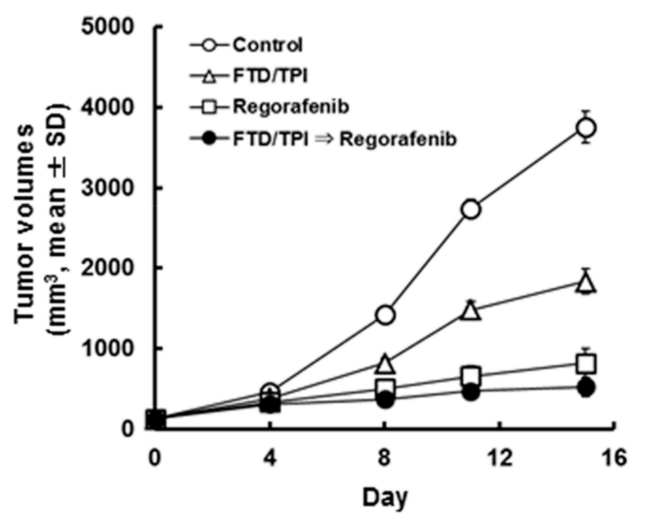

C)

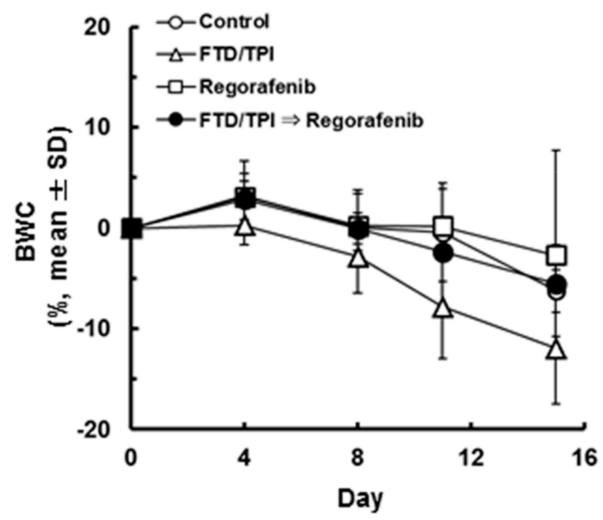

B)

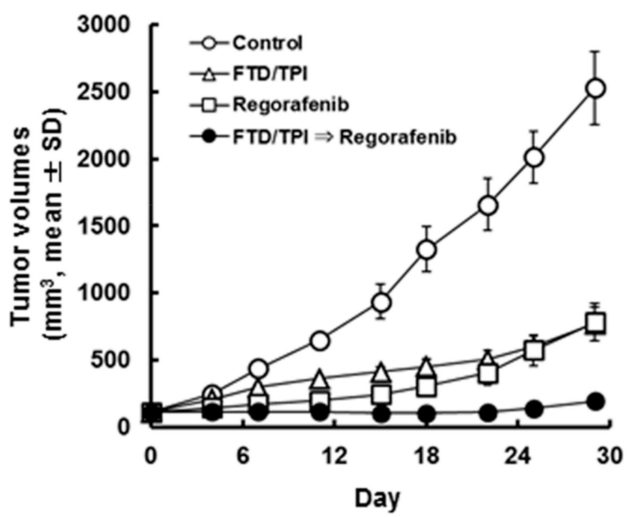

D)

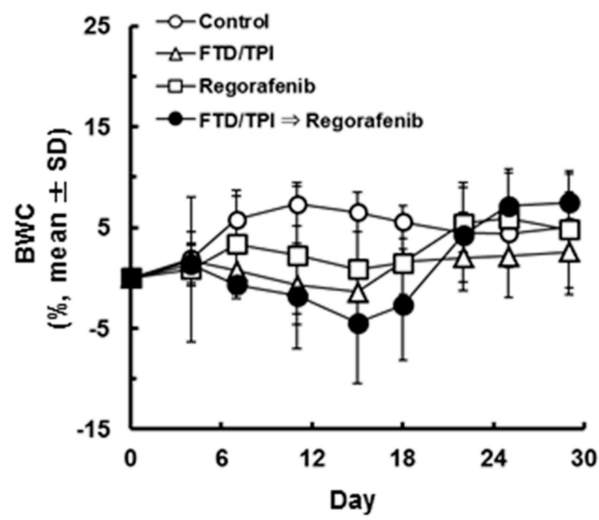

Figure 4. Tumor volume and body weight changes (BWC) in SW620 and COLO205 xenografted mice after daily oral sequential administration of trifluridine/tipiracil (FTD/TPI) and regorafenib. Xenografted mice were randomized on day 0 . FTD $/$ TPI $(150 \mathrm{mg} / \mathrm{kg})$ and regorafenib $(10 \mathrm{mg} / \mathrm{kg})$ were administered orally twice and once daily, respectively, from days 1 to 14 . (A,B) Tumor volume changes and (C,D) body weight changes in SW620 and COLO205 xenografts, respectively. Values indicate mean $\pm \operatorname{SD}(n=6)$. 


\section{Discussion}

In the present study, we evaluated cell death after simultaneous or sequential combination treatment with FTD and regorafenib in SW620, HCT 116, and HT-29 colorectal cancer cells. Interactions between these drugs in SW620 cells, particularly, were schedule-dependent and more effective when treated sequentially with FTD followed by regorafenib than simultaneous or sequential treatment with regorafenib followed by FTD. These effects were associated with reduced TS expression and apoptosis. Furthermore, we found that sequential combined FTD/TPI followed by regorafenib treatment suppressed tumor growth significantly more than either monotherapy in nude mice xenografted with SW620 or COLO205 colorectal cancer cells, with no significant effect on body weight. Thus, the combination treatment of FTD/TPI and regorafenib exerted significant antitumor activity in an in vivo model.

Initially, we evaluated the simultaneous or sequential treatment of FTD and regorafenib in detail in vitro. Our findings suggest that sequential exposure to FTD followed by regorafenib is more effective in SW620 cells than simultaneous treatments or regorafenib followed by FTD exposures (Figure 1). Surprisingly, cell death was observed to a lesser extent after simultaneous treatment or treatment with regorafenib followed by FTD than after treatment with FTD alone in SW620, HCT 116, and HT-29 cells. To elucidate the mechanisms underlying the attenuated efficacy observed for the combination of FTD and regorafenib, we measured the incorporation of FTD into DNA. Lesser FTD was incorporated into DNA after simultaneous treatment with FTD and regorafenib or sequential treatment with regorafenib followed by FTD than that observed after treatment with FTD alone, resulting in reduced FTD-mediated cell death. FTD is reportedly incorporated into DNA during the $S$ phase [17], and regorafenib strongly induces G0/G1 phase arrest [18]. Therefore, simultaneous or pre-treated regorafenib induces accumulation in the G0/G1 phase and then delays progression to the $\mathrm{S}$ phase, which may result in decreased incorporation of FTD into DNA.

In addition, we measured protein expression related to apoptosis and FTD and regorafenib sensitivity to elucidate a cell death mechanism associated with treatments using the combination of FTD and regorafenib. For the first time, we reported a regorafenib-mediated reduction in TS expression. Regorafenib is a sorafenib analog [9], and sorafenib reportedly inhibits E2F-1 expression, resulting in the downregulation of TS expression $[19,20]$. FTD-induced TS expression occurred via its TS inhibitory activity, as previously reported $[5,15]$. TS expression after sequential exposure to FTD followed by regorafenib was lower than that after sequential exposure to regorafenib followed by FTD (Figure 3). These results suggest that regorafenib effectively reduces FTD-induced TS expression. In contrast, when cells were post-treated with FTD, TS expression was induced in cells pre-treated with regorafenib. Sorafenib-mediated reductions in TS expression contributed directly to proapoptotic activity [19]; therefore, regorafenib-mediated reductions in TS expression might be the main factor underlying the apoptosis observed after sequential exposure to FTD followed by regorafenib (Figure 3).

Erlotinib and panitumumab suppress FTD-induced ERK phosphorylation, which is the underlying mechanism associated with the combination effects of FTD and erlotinib or panitumumab [14,15]. Reductions in p-ERK1/2 in HCT 116 and HT-29 cells were also observed in this study after simultaneous exposure to FTD and regorafenib, as well as sequential exposure to FTD followed by regorafenib (Figure 3). However, cell death associated with simultaneous and sequential combinatorial treatments was not confirmed in both cell lines (Figure 1). These results suggest that suppression of p-ERK1/2 via regorafenib may not be related to the combination effects of FTD and regorafenib in this study.

Together, these data suggest that FTD treatment initially increases TS expression, whereas subsequent regorafenib treatment efficiently reduces TS expression, consequently inducing apoptosis in SW620 cells. These results hold only for one of the three cell lines tested; the sequential treatment of FTD followed by regorafenib is more effective in SW620 cells. It remains unclear why the effects of FTD vary depending on the cell line. Further investigations are required to elucidate the 
mechanisms underlying the effect associated with the order of administration of these drugs using in vivo models.

In conclusion, our findings suggest that the sequential treatment of FTD/TPI followed by regorafenib is significantly more effective than either monotherapy in preclinical models. Moreover, FTD followed by regorafenib is more effective than regorafenib followed by FTD in vitro, suggesting that sequential therapy with FTD/TPI prior to regorafenib may be effective in treating colorectal cancer patients.

\section{Materials and Methods}

\subsection{Reagents}

FTD was obtained from Yuki Gosei Kogyo, Co., Ltd. (Tokyo, Japan), whereas 5-chloro-6[(2-iminopyrrolidin-1-yl)methyl]pyrimidine-2,4-(1H,3H)-dione monohydrochloride (tipiracil) was obtained from Taiho Pharmaceutical (Tokyo, Japan). Regorafenib was purchased from Shanghai Haoyuan Chemexpress Co., Ltd. (Shanghai, China), and hydroxypropyl methylcellulose (HPMC) was purchased from Shin-Etsu Chemical (Tokyo, Japan).

\subsection{Cancer Cell Lines}

The SW620 and COLO205 human colon cancer cell lines were purchased from DS Pharma Biomedical Co., Ltd. (Osaka, Japan), and the HCT 116 and HT-29 human colon cancer cell lines were purchased from American Type Culture Collection (ATCC, Manassas, VA, USA). SW620 and COLO205 cells were maintained via implantation into the right axilla of nude mice at 3-week intervals. For in vitro experiments, the cells were cultured at $37^{\circ} \mathrm{C}$ in a humidified atmosphere with $95 \%$ air and $5 \% \mathrm{CO}_{2}$. Dulbecco's modified Eagle medium (DMEM) was used for SW620 and HCT 116 cells and Roswell Park Memorial Institute (RPMI) 1640 medium was used for HT-29 cells, supplemented with $10 \%$ fetal bovine serum (Sigma-Aldrich, St. Louis, MO, USA), $100 \mathrm{U} / \mathrm{mL}$ penicillin, and $100 \mu \mathrm{g} / \mathrm{mL}$ streptomycin (Nacalai Tesque, Inc., Kyoto, Japan). These cells were authenticated in 2014 by analyzing short tandem repeats.

\subsection{Animals}

Male nude mice were purchased from CLEA Japan (Tokyo, Japan) and were housed under specific pathogen-free conditions, with food and water provided ad libitum. All the animal studies were performed according to the guidelines and with the approval of the institutional Animal Care and Use Committee of Taiho Pharmaceutical Co., Ltd. Ethical approval (1 Mar 2013) was obtained prior to conducting the animal experiments.

\subsection{Clonogenic Cell Survival Assay}

The SW620, HCT 116, and HT-29 colorectal cancer cell lines were plated at concentrations of 100-2000 cells/plate in duplicate in six-well plates. Sixteen hours after plating, the cells were treated with FTD and regorafenib as follows: (1) exposure to either 0.1-4.0 $\mu \mathrm{M}$ FTD or 0.4-16.0 $\mu \mathrm{M}$ regorafenib for $24 \mathrm{~h}$, (2) simultaneous exposure to $0.1-4.0 \mu \mathrm{M}$ FTD and $10.0 \mu \mathrm{M}$ regorafenib, (3) sequential exposure to $0.1-4.0 \mu \mathrm{M}$ FTD for $24 \mathrm{~h}$ followed by exposure to $10.0 \mu \mathrm{M}$ regorafenib for $24 \mathrm{~h}$, or (4) sequential exposure to $10.0 \mu \mathrm{M}$ regorafenib for $24 \mathrm{~h}$ followed by exposure to $0.1-4.0 \mu \mathrm{M}$ FTD for $24 \mathrm{~h}$. Eleven to fifteen days after removal of the drug, cells were fixed with $2 \%$ glutaraldehyde and stained with $0.05 \%$ crystal violet; subsequently, the number of colonies containing at least 50 cells was determined. Plating efficiency (PE) was calculated by dividing the number of colonies by the number of cells plated. The surviving fractions (SF) for each treatment were determined by normalizing the average PE of each treatment to the PE for $0.1 \%$ dimethyl sulfoxide (vehicle). 


\subsection{Determination of FTD Incorporation into DNA}

DNA was extracted from cells treated with FTD using NucleoSpin Tissue (Takara Bio, Shiga, Japan), following the manufacturer's protocol. DNA concentrations were determined using Qubit dsDNA Broad-Range Assay Kits (Thermo Fisher Scientific, Waltham, MA, USA), and samples were diluted to $10 \mu \mathrm{g} / \mathrm{mL}$ with distilled water and degraded to nucleosides using a published method [21]. Incorporation (pmol) of FTD into DNA is presented as the amount of FTD per $\mu \mathrm{g}$ of DNA.

\subsection{Immunoblotting}

Cell pellets were lysed in radioimmunoprecipitation assay (RIPA) buffer (Thermo Fisher Scientific) containing a protease inhibitor cocktail and a phosphatase inhibitor cocktail (Nacalai Tesque, Inc.) and incubated for $30 \mathrm{~min}$ on ice. The supernatant was cleared via centrifugation at $15,000 \times g$ for $15 \mathrm{~min}$ at $5{ }^{\circ} \mathrm{C}$. Protein concentrations were determined using a bicinchoninic acid protein assay kit (Thermo Fisher Scientific), and equal amounts of protein (10 $\mu \mathrm{g} / \mathrm{lane})$ were resolved using sodium dodecyl sulfate polyacrylamide gel electrophoresis (SDS-PAGE). An ImageQuant LAS 3000 mini system (GE Healthcare UK Ltd., Buckinghamshire, UK) was used to detect the proteins. The following antibodies were purchased from Cell Signaling Technology (Beverly, MA, USA): anti-PARP (9542S), anti-cleaved PARP (5625S), anti-phospho ERK1/2 (9101S), and anti-ERK1/2 (4696S). Anti-thymidylate synthase (TS) was produced in Taiho Pharm. Co., Ltd., (Tokyo, Japan), and anti- $\beta$-actin (clone AC-74) was purchased from Sigma-Aldrich.

\subsection{Antitumor Activity In Vivo}

The animals were quarantined for one week and then subcutaneously implanted with a solid human tumor of approximately $8 \mathrm{~mm}^{3}$ [22]. In order to evaluate the antitumor activity, the mice were randomized on day 0 based on tumor volume, once the mean tumor volume had reached about $100-300 \mathrm{~mm}^{3}$. Each treatment group consisted of six mice. FTD/TPI was prepared by mixing FTD and TPI at a molar ratio of 1:0.5 in 0.5\% HPMC solution. The dose of FTD/TPI, expressed according to the amount of FTD, was administered orally twice daily from day 1 to 14 at approximately six-hour intervals at the reported effective dose $(150 \mathrm{mg} / \mathrm{kg} /$ day $)[23,24]$. For the control group, vehicle ( $0.5 \%$ HPMC solution) was administered at $10 \mathrm{~mL} / \mathrm{kg}$ in a similar manner. Regorafenib was prepared in polyethylene glycol 400 and aqueous methanesulfonic acid $(125 \mathrm{mM}, 80: 20 \mathrm{v} / \mathrm{v})$ according to a previous report [9], and was administered orally from day 1 to 14 once a day $2-4 \mathrm{~h}$ after the first FTD/TPI administration at the reported effective dose (10 $\mathrm{mg} / \mathrm{kg} /$ day) [9].

Tumor diameters were measured twice a week, and tumor volume was estimated as $0.5 \times$ length $\times$ width $^{2}$. Relative tumor volume (RTV) was calculated using the following formula:

$$
\mathrm{RTV}=\text { (tumor volume on measured day)/(tumor volume on day } 0 \text { ). }
$$

On day 15 or 29 , the tumor growth inhibition ratio (TGI, \%) was calculated using the following formula:

$$
\text { TGI }(\%)=[1-(\text { RTV in experimental group }) /(\text { RTV in control group })] \times 100(\%) .
$$

Groups were terminated after tumors had reached the ethically allowed limits. Finally, toxicity was evaluated based on BWC, which was calculated using the following formula:

BWC $(\%)=[($ body weight on measured day - body weight on day 0$) /$ body weight on day 0$] \times 100(\%)$. 
Toxicity was defined as a BWC loss of more than $20 \%$ or toxic death. The experimental endpoint was defined as the day on which the average tumor volume for the average body weight within each group reached more than $10 \%$.

\subsection{Statistical Analysis}

Significant differences in the clonogenic cell survival assay were analyzed using the student's $t$-test. Significant differences in the mean RTV between the treated and the control groups on day 15 or 29 were analyzed using the Aspin-Welch two-sided $t$-test. The combinational antitumor effect of FTD/TPI and regorafenib was analyzed according to a closed testing procedure using the Aspin-Welch two-tailed $t$-test [25]. Differences with an associated $p$ value of less than 0.05 were considered significant. $P$ values were calculated using EXSUS (ver. 8.1 CAC EXCARE Corp., Osaka, Japan).

Author Contributions: K.M. (Kazuaki Matsuoka) conceived, designed, performed the experiments, analyzed the data, and wrote the paper. F.N. performed the experiments and analyzed the data. N.T., H.O., K.M. (Kenichi Matsuo), and T.T. conceived and designed the experiments.

Funding: This research received no external funding.

Acknowledgments: We would like to thank Editage (www.editage.jp) for English language editing.

Conflicts of Interest: All authors are employees of Taiho Pharmaceutical Co., Ltd. (Tokyo, Japan).

$\begin{array}{ll}\text { Abbreviations } \\ \text { BWC } & \text { Body weight change } \\ \text { CRC } & \text { Colorectal cancer } \\ \text { DMEM } & \text { Dulbecco's modified Eagle medium } \\ \text { ERK } & \text { Extracellular signal-related kinase } \\ \text { FBS } & \text { Fetal bovine serum } \\ \text { FTD } & \text { Trifluridine } \\ \text { LV } & \text { Leucovorin } \\ \text { PARP } & \text { Poly(ADP-ribose) polymerase } \\ \text { PE } & \text { Plating efficiency } \\ \text { p-ERK1/2 } & \text { Phosphorylated extracellular signal-related kinase } \\ & \text { 1/2 } \\ \text { RIPA } & \text { Radioimmunoprecipitation assay } \\ \text { RTV } & \text { Relative tumor volume } \\ \text { SDS-PAGE } & \text { Sodium dodecyl sulfate polyacrylamide gel } \\ & \text { electrophoresis } \\ \text { SF } & \text { Surviving fractions } \\ \text { TGI } & \text { Tumor growth inhibition } \\ \text { TS } & \text { Thymidylate synthase } \\ \text { TPI } & \text { Tipiracil hydrochloride } \\ \text { 5-FU } & \text { 5-Fluorouracil } \\ & \end{array}$

\section{References}

1. Gustavsson, B.; Carlsson, G.; Machover, D.; Petrelli, N.; Roth, A.; Schmoll, H.J.; Tveit, K.M.; Gibson, F. A review of the evolution of systemic chemotherapy in the management of colorectal cancer. Clin. Colorectal Cancer 2015, 14, 1-10. [CrossRef] [PubMed]

2. Scheithauer, W.; Rosen, H.; Kornek, G.V.; Sebesta, C.; Depisch, D. Randomised comparison of combination chemotherapy plus supportive care with supportive care alone in patients with metastatic colorectal cancer. BMJ 1993, 306, 752-755. [CrossRef] [PubMed]

3. Heidelberger, C.; Parsons, D.G.; Remy, D.C. Syntheses of 5-trifluoromethyluracil and 5-trifluoromethyl-2'-deoxyuridine. J. Med. Chem. 1964, 7, 1-5. [CrossRef] [PubMed]

4. Tanaka, N.; Sakamoto, K.; Okabe, H.; Fujioka, A.; Yamamura, K.; Nakagawa, F.; Nagase, H.; Yokogawa, T.; Oguchi, K.; Ishida, K.; et al. Repeated oral dosing of TAS-102 confers high trifluridine incorporation into 
DNA and sustained antitumor activity in mouse models. Oncol. Rep. 2014, 32, 2319-2326. [CrossRef] [PubMed]

5. Matsuoka, K.; Iimori, M.; Niimi, S.; Tsukihara, H.; Watanabe, S.; Kiyonari, S.; Kiniwa, M.; Ando, K.; Tokunaga, E.; Saeki, H.; et al. Trifluridine induces p53-dependent sustained G2 phase arrest with its massive misincorporation into DNA and few DNA strand breaks. Mol. Cancer Ther. 2015, 14, 1004-1013. [CrossRef] [PubMed]

6. Langenbach, R.J.; Danenberg, P.V.; Heidelberger, C. Thymidylate synthetase: Mechanism of inhibition by 5-fluoro-2'-deoxyuridylate. Biochem. Biophys. Res. Commun. 1972, 48, 1565-1571. [CrossRef]

7. Fukushima, M.; Suzuki, N.; Emura, T.; Yano, S.; Kazuno, H.; Tada, Y.; Yamada, Y.; Asao, T. Structure and activity of specific inhibitors of thymidine phosphorylase to potentiate the function of antitumor 2'-deoxyribonucleosides. Biochem. Pharmacol. 2000, 59, 1227-1236. [CrossRef]

8. Mayer, R.J.; Van Cutsem, E.; Falcone, A.; Yoshino, T.; Garcia-Carbonero, R.; Mizunuma, N.; Yamazaki, K.; Shimada, Y.; Tabernero, J.; Komatsu, Y.; et al. Randomized trial of TAS-102 for refractory metastatic colorectal cancer. N. Engl. J. Med. 2015, 372, 1909-1919. [CrossRef] [PubMed]

9. Wilhelm, S.M.; Dumas, J.; Adnane, L.; Lynch, M.; Carter, C.A.; Schutz, G.; Thierauch, K.H.; Zopf, D. Regorafenib (BAY 73-4506): A new oral multikinase inhibitor of angiogenic, stromal and oncogenic receptor tyrosine kinases with potent preclinical antitumor activity. Int. J. Cancer 2011, 129, 245-255. [CrossRef] [PubMed]

10. Grothey, A.; Van Cutsem, E.; Sobrero, A.; Siena, S.; Falcone, A.; Ychou, M.; Humblet, Y.; Bouche, O.; Mineur, L.; Barone, C.; et al. Regorafenib monotherapy for previously treated metastatic colorectal cancer (CORRECT): An international, multicentre, randomised, placebo-controlled, phase 3 trial. Lancet 2013, 381, 303-312. [CrossRef]

11. Masuishi, T.; Taniguchi, H.; Hamauchi, S.; Komori, A.; Kito, Y.; Narita, Y.; Tsushima, T.; Ishihara, M.; Todaka, A.; Tanaka, T.; et al. Regorafenib versus trifluridine/tipiracil for refractory metastatic colorectal cancer: A retrospective comparison. Clin. Colorectal Cancer 2017, 16, e15-e22. [CrossRef] [PubMed]

12. Moriwaki, T.; Fukuoka, S.; Taniguchi, H.; Takashima, A.; Kumekawa, Y.; Kajiwara, T.; Yamazaki, K.; Esaki, T.; Makiyama, C.; Denda, T.; et al. Propensity score analysis of regorafenib versus trifluridine/tipiracil in patients with metastatic colorectal cancer refractory to standard chemotherapy (REGOTAS): A Japanese Society for Cancer of the Colon and Rectum Multicenter Observational Study. Oncologist 2018, 23, 7-15. [CrossRef] [PubMed]

13. Schmieder, R.; Hoffmann, J.; Becker, M.; Bhargava, A.; Muller, T.; Kahmann, N.; Ellinghaus, P.; Adams, R.; Rosenthal, A.; Thierauch, K.H.; et al. Regorafenib (BAY 73-4506): Antitumor and antimetastatic activities in preclinical models of colorectal cancer. Int. J. Cancer 2014, 135, 1487-1496. [CrossRef] [PubMed]

14. Bijnsdorp, I.V.; Kruyt, F.A.; Fukushima, M.; Smid, K.; Gokoel, S.; Peters, G.J. Molecular mechanism underlying the synergistic interaction between trifluorothymidine and the epidermal growth factor receptor inhibitor erlotinib in human colorectal cancer cell lines. Cancer Sci. 2010, 101, 440-447. [CrossRef] [PubMed]

15. Baba, Y.; Tamura, T.; Satoh, Y.; Gotou, M.; Sawada, H.; Ebara, S.; Shibuya, K.; Soeda, J.; Nakamura, K. Panitumumab interaction with TAS-102 leads to combinational anticancer effects via blocking of EGFR-mediated tumor response to trifluridine. Mol. Oncol. 2017, 11, 1065-1077. [CrossRef] [PubMed]

16. Peters, G.J.; Backus, H.H.; Freemantle, S.; van Triest, B.; Codacci-Pisanelli, G.; van der Wilt, C.L.; Smid, K.; Lunec, J.; Calvert, A.H.; Marsh, S.; et al. Induction of thymidylate synthase as a 5-fluorouracil resistance mechanism. Biochim. Biophys. Acta 2002, 1587, 194-205. [CrossRef]

17. Kitao, H.; Morodomi, Y.; Niimi, S.; Kiniwa, M.; Shigeno, K.; Matsuoka, K.; Kataoka, Y.; Iimori, M.; Tokunaga, E.; Saeki, H.; et al. The antibodies against 5-bromo-2'-deoxyuridine specifically recognize trifluridine incorporated into DNA. Sci. Rep. 2016, 6, 25286. [CrossRef] [PubMed]

18. Zhang, W.J.; Li, Y.; Wei, M.N.; Chen, Y.; Qiu, J.G.; Jiang, Q.W.; Yang, Y.; Zheng, D.W.; Qin, W.M.; Huang, J.R.; et al. Synergistic antitumor activity of regorafenib and lapatinib in preclinical models of human colorectal cancer. Cancer Lett. 2017, 386, 100-109. [CrossRef] [PubMed]

19. Takeuchi, A.; Shiota, M.; Tatsugami, K.; Yokomizo, A.; Eto, M.; Inokuchi, J.; Kuroiwa, K.; Kiyoshima, K.; Naito, S. Sorafenib augments cytotoxic effect of S-1 in vitro and in vivo through TS suppression. Cancer Chemother. Pharmacol. 2011, 68, 1557-1564. [CrossRef] [PubMed] 
20. Zhai, J.M.; Yin, X.Y.; Lai, Y.R.; Hou, X.; Cai, J.P.; Hao, X.Y.; Liang, L.J.; Zhang, L.J. Sorafenib enhances the chemotherapeutic efficacy of $\mathrm{S}-1$ against hepatocellular carcinoma through downregulation of transcription factor E2F-1. Cancer Chemother. Pharmacol. 2013, 71, 1255-1264. [CrossRef] [PubMed]

21. Matsuoka, K.; Nakagawa, F.; Kobunai, T.; Takechi, T. Trifluridine/tipiracil overcomes the resistance of human gastric 5-fluorouracil-refractory cells with high thymidylate synthase expression. Oncotarget 2018, 9, 13438-13450. [CrossRef] [PubMed]

22. Nukatsuka, M.; Saito, H.; Nakagawa, F.; Tsujimoto, H.; Sakamoto, K.; Tsukioka, S.; Uchida, J.; Kiniwa, M.; Kobunai, T.; Takechi, T. Combination therapy using oral S-1 and targeted agents against human tumor xenografts in nude mice. Exp. Ther. Med. 2012, 3, 755-762. [CrossRef] [PubMed]

23. Emura, T.; Nakagawa, F.; Fujioka, A.; Ohshimo, H.; Yokogawa, T.; Okabe, H.; Kitazato, K. An optimal dosing schedule for a novel combination antimetabolite, TAS-102, based on its intracellular metabolism and its incorporation into DNA. Int. J. Mol. Med. 2004, 13, 249-255. [CrossRef] [PubMed]

24. Emura, T.; Suzuki, N.; Fujioka, A.; Ohshimo, H.; Fukushima, M. Potentiation of the antitumor activity of alpha, alpha, alpha-trifluorothymidine by the co-administration of an inhibitor of thymidine phosphorylase at a suitable molar ratio in vivo. Int. J. Oncol. 2005, 27, 449-455. [CrossRef] [PubMed]

25. Bauer, P.; Röhmel, J.; Maurer, W.; Hothorn, L. Testing strategies in multi-dose experiments including active control. Stat. Med. 1998, 17, 2133-2146. [CrossRef]

(C) 2018 by the authors. Licensee MDPI, Basel, Switzerland. This article is an open access article distributed under the terms and conditions of the Creative Commons Attribution (CC BY) license (http:// creativecommons.org/licenses/by/4.0/). 